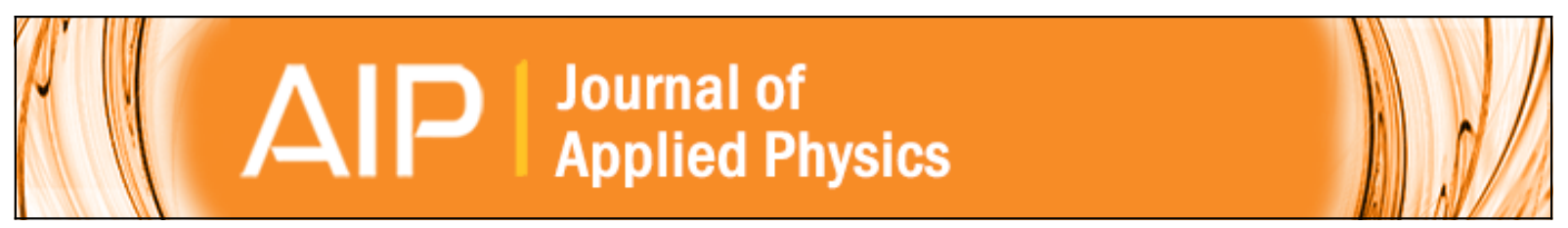

\title{
Improved efficiency of P3HT:PCBM solar cells by incorporation of silver oxide interfacial layer
}

Sayantan Das and T. L. Alford

Citation: Journal of Applied Physics 116, 044905 (2014); doi: 10.1063/1.4891246

View online: http://dx.doi.org/10.1063/1.4891246

View Table of Contents: http://scitation.aip.org/content/aip/journal/jap/116/4?ver=pdfcov

Published by the AIP Publishing

\section{Articles you may be interested in}

Indium tin oxide-free transparent and conductive electrode based on $\mathrm{SnOx}|\mathrm{Ag}| \mathrm{SnOx}$ for organic solar cells J. Appl. Phys. 116, 023105 (2014); 10.1063/1.4886225

Order of decay of mobile charge carriers in P3HT:PCBM solar cells

Appl. Phys. Lett. 103, 043307 (2013); 10.1063/1.4816720

Analysis of voltage and temperature dependent photocurrent collection in $\mathrm{p} 3 \mathrm{ht} / \mathrm{pcbm}$ solar cells

J. Appl. Phys. 112, 114514 (2012); 10.1063/1.4768910

Erratum: "Shockley Read Hall recombination in P3HT:PCBM solar cells as observed under ultra low light intensities" [109(6), 064501 (2011)]

J. Appl. Phys. 112, 029902 (2012); 10.1063/1.4737789

Improvement of efficiency of dye-sensitized solar cells by reduction of internal resistance

Appl. Phys. Lett. 86, 213501 (2005); 10.1063/1.1925773

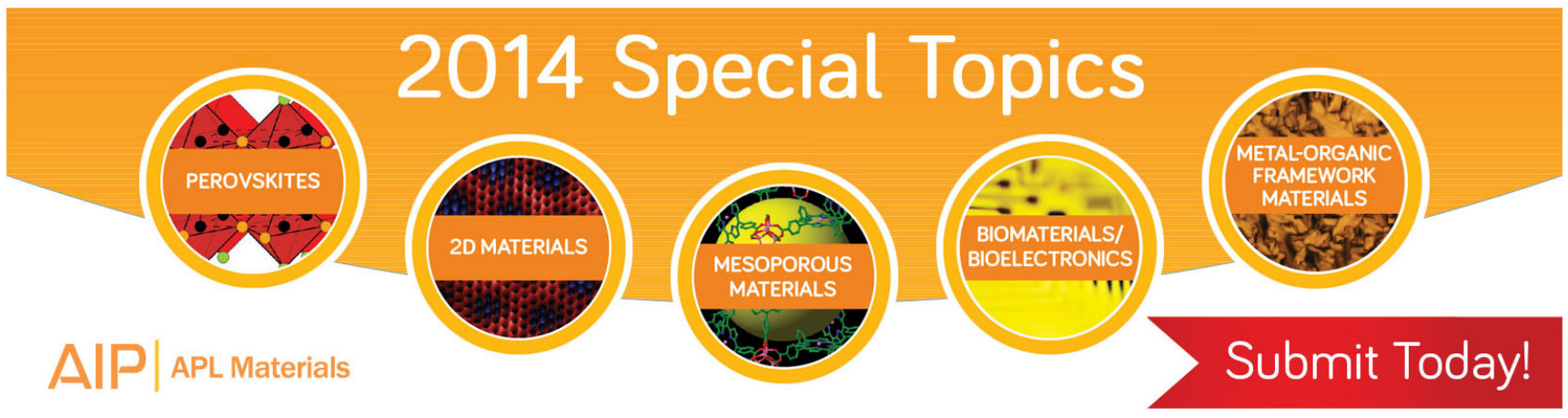




\title{
Improved efficiency of P3HT:PCBM solar cells by incorporation of silver oxide interfacial layer
}

\author{
Sayantan Das and T. L. Alford ${ }^{\text {a) }}$ \\ Department of Chemistry and Biochemistry and School for Engineering of Matter, Transport and Energy, \\ Arizona State University, Tempe, Arizona 85287, USA
}

(Received 13 May 2014; accepted 14 July 2014; published online 24 July 2014)

\begin{abstract}
In recent years, a substantial amount of research has been focused on identifying suitable interfacial layers in organic light-emitting diodes and organic solar cells which has efficient charge transport properties. In this work, a very thin layer of $\mathrm{AgOx}$ is deposited on top of the ITO layer along with PEDOT:PSS and is observed that the solar cells having the AgOx interfacial layer showed a $28 \%$ increase in power conversion efficiency in comparison to that of the control cell. The enhancement in efficiency has been ascribed to improvements in fill factor as well as the increase in shunt resistance and decrease in the series resistance of the solar cells. An equivalent circuit model is also provided to understand the changes in the series and shunt resistances in the AgOx modified devices. (C) 2014 AIP Publishing LLC. [http://dx.doi.org/10.1063/1.4891246]
\end{abstract}

\section{INTRODUCTION}

The use of organic solar cells (OSCs) as a renewable electrical energy source offers a great technological advantage because of its cost-effective and low temperature fabrication process. ${ }^{1-4}$ Over the past two decades, OSC devices have witnessed a steady evolution as evidenced by the development of new designs, newer materials and interfacial layers which now exhibit very high power conversion efficiencies (PCEs) ${ }^{5-10}$ Bulk-heterojunction (BHJ) structures in OSCs are one of the most promising alternatives to the more expensive silicon solar cells. For optimal functioning of OSCs, efficient charge carrier extraction from the active layer to the respective electrodes is essential. ${ }^{8}$ This is highly controlled by the character of the interfaces of each layer. One approach of efficient charge extraction is to match the highest occupied molecular orbital (HOMO) and the lowest unoccupied (LUMO) energies of the active layer with the work functions of the anode and cathode, respectively. ${ }^{11,12}$ Previous investigations show that the performance improvement of an organic solar cell through the introduction of self-assembled monolayers of molecules on ITO substrates with dipole moment of appropriate direction and magnitude. ${ }^{13,14}$ This method effectively changes the work function of ITO and decreases the injection barrier between ITO and the HOMO level of the active layer in organic solar cells. Another approach shows that the formation of an interfacial energy step could improve the charge collection efficiency in organic photovoltaic devices and thereby increase their efficiency. ${ }^{15,16}$

In OSCs, a blend of regioregular poly(3-hexylthiophene) (P3HT) and the fullerene derivative [6,6]-phenyl-C61 butyric acid methyl ester (PCBM) is the most widely researched donor and acceptor materials. ${ }^{17}$ The blend of these two materials (P3HT:PCBM) forms a phase-separated (BHJ) nanostructure that offers a large interfacial area for efficient exciton dissociation. $^{18}$ A thin poly(3,4-ethylenedioxythiophene):

\footnotetext{
a) Author to whom correspondence should be addressed. Electronic mail: TA@asu.edu. Tel.: 0014809657471.
}

poly(styrenesulfonate) (PEDOT:PSS) layer on top of the anode is commonly used as an ande contact. This is because the work function of PEDOT:PSS matches well with the HOMO of P3HT and thus can effectively extract holes from the active layer. Besides, the thin film of PEDOT:PSS planarizes the ITO surface without significantly affecting the light absorption by the active layer. ${ }^{19}$ Other benefits of using PEDOT:PSS include its high electrical conductivity and low temperature solution processability, which makes it an ideal hole transport material in flexible organic solar cell devices. Even though PEDOT:PSS has been used widely as hole transport layer, its electrical inhomogeneity ${ }^{20}$ prevents it to be an efficient electron blocking layer. ${ }^{21}$ Moreover, the acidic and hygroscopic nature of PEDOT:PSS can result in degraded device performance. ${ }^{22,23}$ Metal oxides like MoOx, VOx, NiOx, and WOx have been used as a substitute to PEDOT: PSS; however, these metal oxides form rough interfaces which can result in degraded device performances. ${ }^{24-26}$

In this work, OSC devices with a AgOx interfacial layer added in between the ITO and PEDOT:PSS and their properties are investigated. The AgOx and PEDOT:PSS layers form a composite hole transport layer. Increased fill factor (FF) and power conversion efficiency (PCE) of the solar cell devices are obtained with the implementation of the AgOx interfacial layer. The interfacial modification also results in improved shunt resistances suggesting lesser charge recombination due to cascading hole transport process. Moreover, this technique reduces the physical contact of PEDOT:PSS with ITO layer by the introduction of the AgOx thin film.

\section{EXPERIMENTAL DETAILS}

\section{A. Reagents and materials}

PEDOT:PSS (CleviousPVP AI 4083) was purchased from H.C. Stark Company. The electron donor material regioregular poly (3-hexylthiophene) (P3HT) was purchased from Reike Metals, Inc. The electron acceptor material [6,6]-phenyl C61 butyric acid methyl ester $\left(\mathrm{PC}_{61} \mathrm{BM}\right)$ and 1,2-dichlorobenzene 

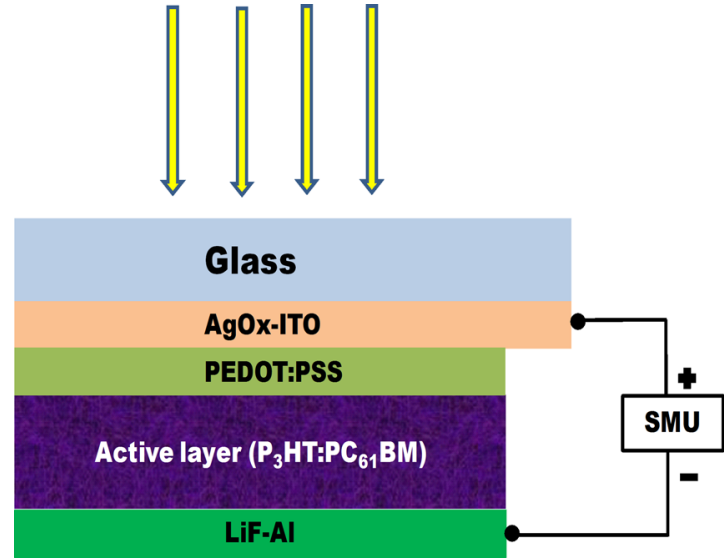

FIG. 1. Schematic configuration of the organic solar cells device.

were purchased from Sigma Aldrich. All these commercially available chemicals were used as-received without further purification.

\section{B. Electrode modification}

All devices in this work were prepared on patterned ITO (40 $\Omega \mathrm{sq}^{-1}$ ) coated glass substrates. The substrates were cleaned in sequential ultrasonic baths of acetone, methanol, and isopropanol, followed by ultraviolet ozone (UVO) treatment for $15 \mathrm{~min}$. Silver oxide (AgOx) layer was then deposited on top of ITO by first depositing $1 \mathrm{~nm}$ thick Ag metal by thermal evaporation at a pressure of $\sim 10^{-7}$ Torr followed by UVO treatment for $1 \mathrm{~min}$. This led to the formation of silver oxide as confirmed by X-ray photoelectron spectroscopy (XPS) analysis. The optical transmittance of bare ITO and $\mathrm{AgOx}$ modified ITO electrodes were measured using Ocean Optics double channel spectrometer (model DS200) in a wavelength range of $300-800 \mathrm{~nm}$. The oxidation state of $\mathrm{Ag}$ in the modified ITO electrode was determined by XPS using a VG-220IXL spectrometer with monochromatic $\mathrm{Al} K \alpha$ radiation $(1486.6 \mathrm{eV}$, line width $=0.8 \mathrm{eV})$. The pressure in the analyzing chamber was kept at a level of $10^{-9}$ Torr while recording the spectrum. The spectrometer had an energy resolution of $0.4 \mathrm{eV}$. All the binding energies were corrected with reference to $\mathrm{C}(1 \mathrm{~s})$ at $284.6 \mathrm{eV}$.

\section{OSC fabrication}

Electron donor material P3HT and electron acceptor material $\mathrm{PC}_{61} \mathrm{BM}$ were weighed $(1: 1 \mathrm{w} / \mathrm{w})$ and dissolved in 1,2-dichlorobenzene (DCB) in a nitrogen-filled glove box. The solution was stirred at room temperature for a minimum of 12 hours. The PEDOT:PSS solution was spin-coated at $5000 \mathrm{rpm}$ for $60 \mathrm{~s}$ onto freshly prepared electrodes, followed by baking on a hot plate at $150^{\circ} \mathrm{C}$ from $15 \mathrm{~min}$. Photoactive layers were then spin-coated from $\mathrm{P} 3 \mathrm{HT}: \mathrm{PC}_{61} \mathrm{BM}$ blends at $600 \mathrm{rpm}$ for $1 \mathrm{~min}$, then annealed for $30 \mathrm{~min}$ at $120^{\circ} \mathrm{C}$ on a hot plate inside the glove box. This corresponded to layer thickness of $250 \mathrm{~nm}$. Finally, each devices were completed by thermal deposition of $0.7 \mathrm{~nm}$ of $\mathrm{LiF}$ followed by $80 \mathrm{~nm}$ thick $\mathrm{Al}$ cathodes in vacuum (about $1 \times 10^{-6}$ Torr). A shadow mask was used during thermal evaporation to define an active area of $0.2 \mathrm{~cm}^{2}$. Both type of devices (control and AgOx modified) were then transferred to the solar simulator for testing. The schematic of the device with $\mathrm{AgOx}$ interfacial layer is shown in Fig. 1.

\section{Device testing}

Current density-voltage (J-V) measurements were performed under simulated AM 1.5 global solar irradiation $\left(100 \mathrm{~mW} / \mathrm{cm}^{2}\right)$ using a xenon-lamp solar simulator (Spectra Physics, Oriel Instruments, USA). The light source was calibrated with a standard $\mathrm{Si}$ photodiode reference cell (Hamamatsu Photonics, Japan) prior to measurement. The external quantum efficiency (EQE) of the devices was determined as a function of wavelength from the photocurrent generated in the device from an incident monochromatic light source using an Optronic Lab OL750 series spectroradiometer. The EQE was determined by comparing this photocurrent to the monochromatic beam intensity measured using a calibrated Si photodetector.

\section{RESULTS AND DISCUSSION}

For samples consisting of UVO-treated $1 \mathrm{~nm} \mathrm{Ag}$ on ITO, XPS analysis is utilized to analyze the different oxidation states of the $\mathrm{AgOx}$ thin film. Figure 2 shows a wide range spectrum and high-resolution $\mathrm{Ag} 3 \mathrm{~d}_{5 / 2}$ and $\mathrm{O} 1 \mathrm{~s} \mathrm{spec-}$ tra for AgOx thin films on ITO. The Ag $3 \mathrm{~d}_{5 / 2}$ signal can be deconvoluted into two peaks, and the corresponding binding energies observed for the $\mathrm{AgOx}$ films are $367.8 \mathrm{eV}$ and $368.2 \mathrm{eV}$, which are consistent with those of $\mathrm{AgO}$ and $\mathrm{Ag}_{2} \mathrm{O}$, respectively. ${ }^{27}$ The estimated percentages of the two deconvoluted peaks $\left(\mathrm{Ag}^{2+}\right.$ to $\mathrm{Ag}^{+}$ratio 72:28) indicates that $\mathrm{Ag}^{2+}$ is the dominant silver oxidation state in the AgOx thin films after ozonization. Deconvolution of the O $1 \mathrm{~s}$ spectrum gives
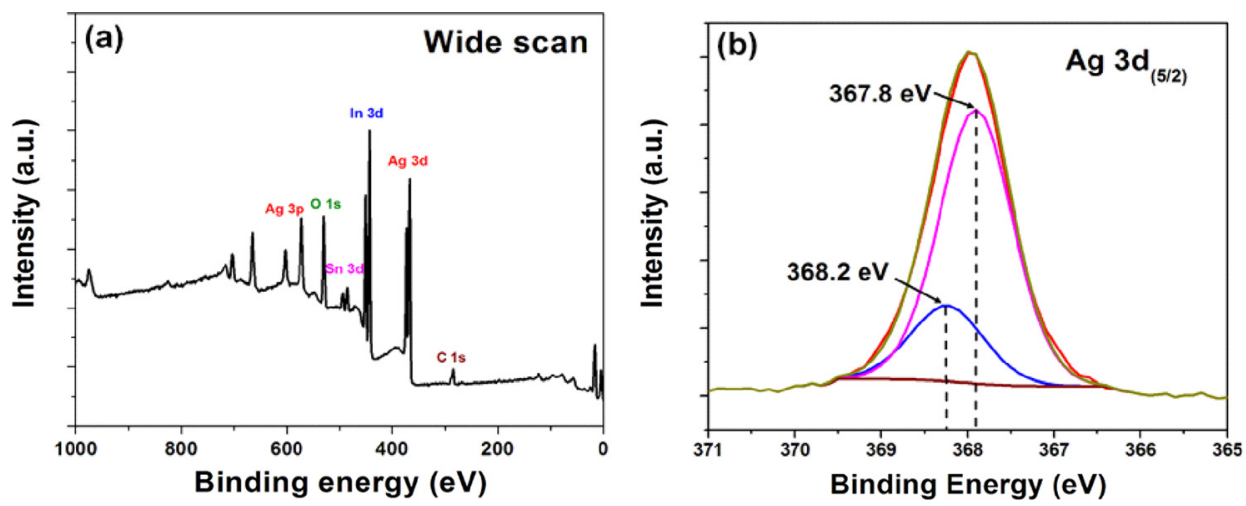

FIG. 2. (a) Full scan XPS showing Ag $3 d$, In $3 \mathrm{~d}$ and $\mathrm{Sn} 3 \mathrm{~d}$ peaks for $\mathrm{AgOx}$ film on the top of ITO substrate (b) the deconvoluted peaks of $\mathrm{Ag} 3 \mathrm{~d}_{5 / 2}$ with binding energies at $367.8 \mathrm{eV}$ and $368.2 \mathrm{eV}$ for $\mathrm{Ag}^{+2}$ and $\mathrm{Ag}^{+1}$, respectively. 


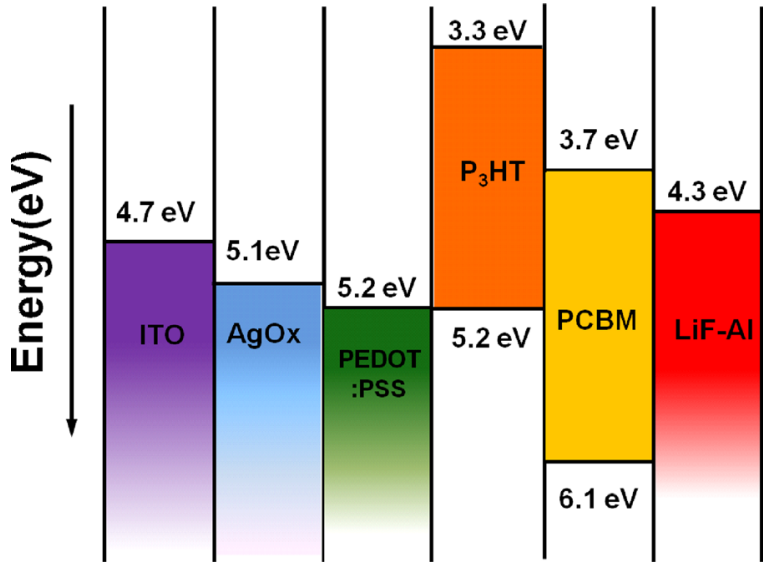

FIG. 3. Energy level diagram for a P3HT:PCBM bulk-heterojunction solar cell with $\mathrm{AgOx}$ interfacial layer. The published values of valence band, conduction band, and the Fermi level energies of the different materials are shown here.

information regarding the chemical state of oxygen in the $\mathrm{AgOx}$ films on ITO. The silver oxide (AgOx) is a p-type semiconductor with its work function ranging between 4.7-5.2 eV depending on the processing conditions. ${ }^{28}$ The energy band diagram showing the cascade type hole transport due to this hybridization is represented in Fig. 3.

Interfacial morphology plays a crucial role in both charge collection and transport in organic photovoltaic devices. Greater surface roughness over the electrode surface can cause formation of defects which can decrease the device efficiency. ${ }^{29}$ Figure 4 shows the $4 \times 4 \mu \mathrm{m}^{2}$ tapping mode AFM images of bare ITO and AgOx modified ITO. The root-mean-square (rms) roughness of a bare ITO substrate was $0.5 \mathrm{~nm}$; while, the rms roughness of ITO substrates with $\mathrm{AgOx}$ on top increased to a value of $4.2 \mathrm{~nm}$. Thus, adding the AgOx layer increased the surface morphology significantly. It should be noted here that ITO layer is not fully covered by $\mathrm{AgOx}$ completely due to the formation of $\mathrm{Ag}$ islands during evaporation.

Previous investigations by our group and other groups suggest that the absorption band of $\mathrm{P} 3 \mathrm{HT}: \mathrm{PC}_{61} \mathrm{BM}$ blend ( $1: 1$ weight ratio) is $400-600 \mathrm{~nm}$ and the maximum absorption wavelength for annealed films are $\sim 510 \mathrm{~nm} .{ }^{30,31}$ Figure 5 shows the optical transmittance of bare ITO and AgOx/ ITO layer over the range $400-800 \mathrm{~nm}$. For this range, the average transmittance of the ITO coated glass substrate is about $77 \%$. Upon insertion of the thin $\mathrm{AgOx}$ layer the average transmittance slightly reduces to $74 \%$ which results

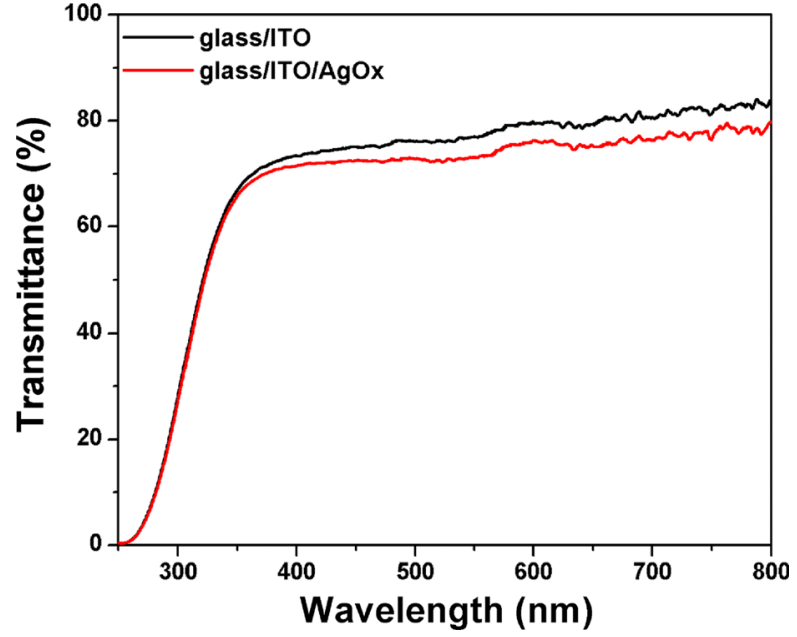

FIG. 5. Optical transmittance of bare ITO and AgOx/ITO films.

in the reduction in number of absorbed photons passing through the anode and correspondingly decrease photocurrent generation.

Figure 6(a) shows the forward bias current density-voltage $(J-V)$ characteristics under darkness where current density is significantly enhanced at a given voltage in case of devices consisting of $\mathrm{AgOx}$ as the interfacial layer. The $J-V$ characteristics for the devices under AM 1.5 G illuminations with an overall intensity of $100 \mathrm{~mW} / \mathrm{cm}^{2}$ is shown in Fig. 6(b). As expected, the open circuit voltage (Voc) value remains almost the same since the active layer fabrication condition and the cathode layer deposition remain constant. The control device with ITO/PEDOT:PSS anode demonstrated a PCE of $1.74 \%$. The open circuit voltage (Voc) and the current density $\left(J_{S c}\right)$ of the control devices were $0.60 \mathrm{~V}$ and $8.76 \mathrm{~mA} / \mathrm{cm}^{2}$, respectively. Although the $V O C$ and $J S C$ for the devices contenting an $\mathrm{AgOx}$ interfacial layer decreased very slightly to $0.58 \mathrm{~V}$ and $8.64 \mathrm{~mA} / \mathrm{cm}^{2}$, respectively, there was a moderate increase in the fill factor $(F F)$ of these devices which led to the increase in the PCE. The $F F$ in devices consisting of the AgOx interfacial layer was 36\% higher when compared to the control devices. Figure 7 shows the EQE results of the devices with and without $\mathrm{AgOx}$ interlayer. In the range between 400 and $600 \mathrm{~nm}$, both devices show efficient photoconversion efficiency with EQE values over $50 \%$. However, the application of $\mathrm{AgOx}$ shows a slight decrease in the donor contribution to EQE (between $400 \mathrm{~nm}$ and $600 \mathrm{~nm}$ ) and results in slight decrease in the short circuit current (as shown in Table I).
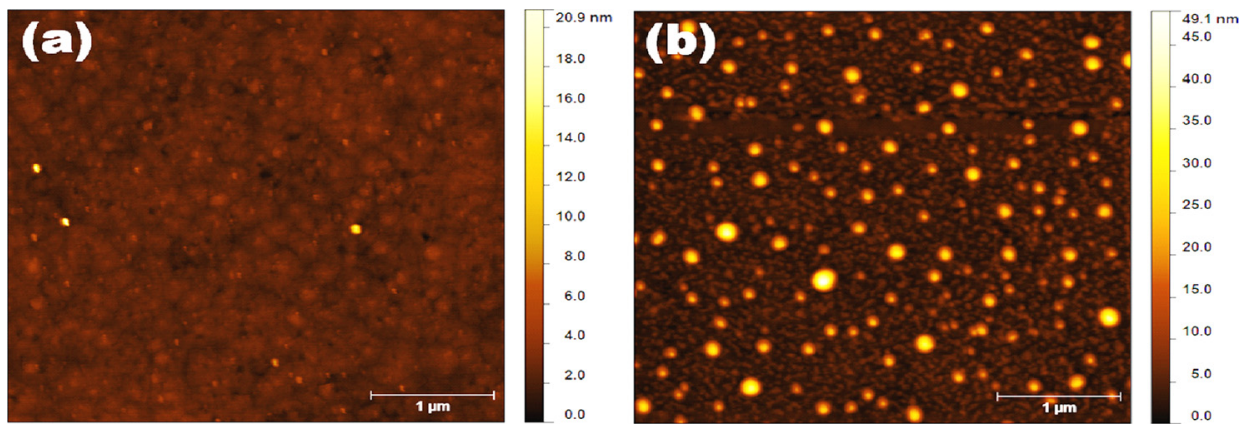

FIG. 4. AFM surface images of (a) bare ITO and (b) $\mathrm{AgOx}$ modified ITO (scan size: $4 \mu \mathrm{m} \times 4 \mu \mathrm{m}$ ). 

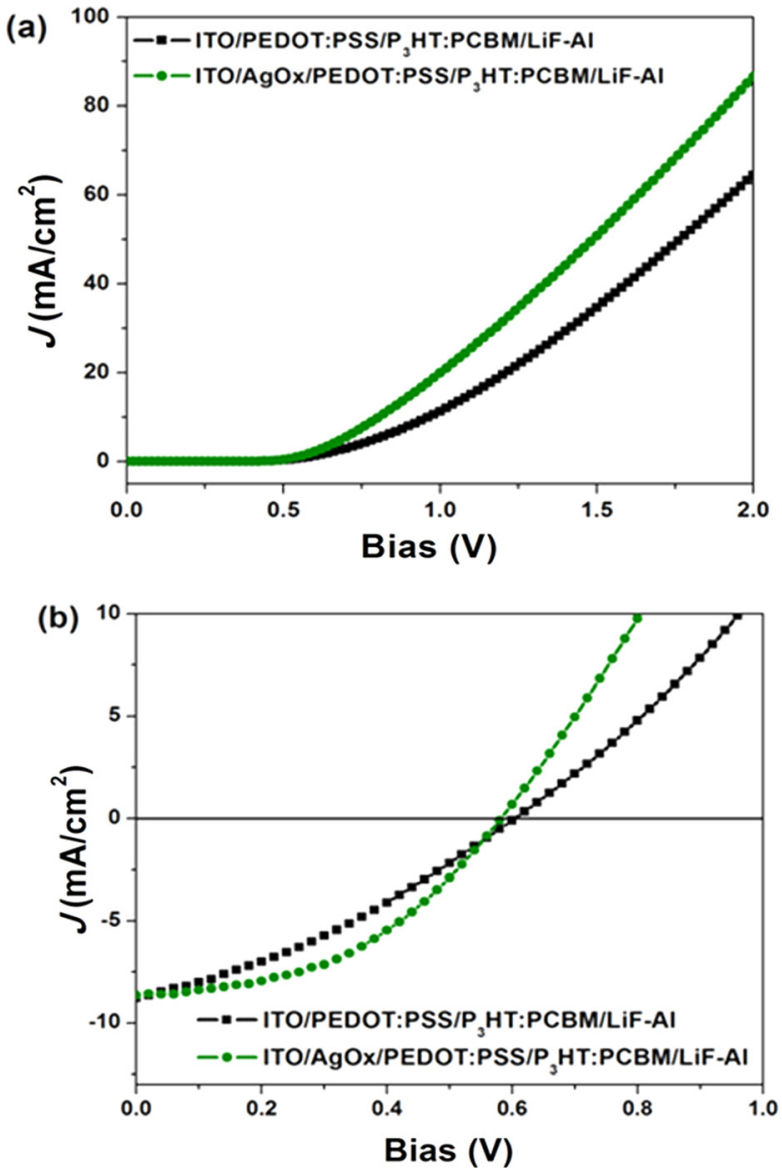

FIG. 6. Current-density $(J-V)$ characteristics of the bulk-heterojunction solar cell with bare ITO and AgOx/ITO anode layer (a) in dark and (b) under illumination (AM 1.5, $\left.100 \mathrm{~mW} / \mathrm{cm}^{2}\right)$.

When placed under simulated solar illumination, an OSC solar cell may be modeled by an equivalent circuit (EC). This circuit is typically constructed using a single-diode in parallel with a current source as shown in Fig. 8(a) and described ${ }^{32}$

$$
J=J_{p h}-J_{o}\left(\exp \left[\frac{q\left(V+J R_{s}\right)}{n k_{B} T}\right]-1\right)-\frac{V+J R_{s}}{J R_{s h}},
$$

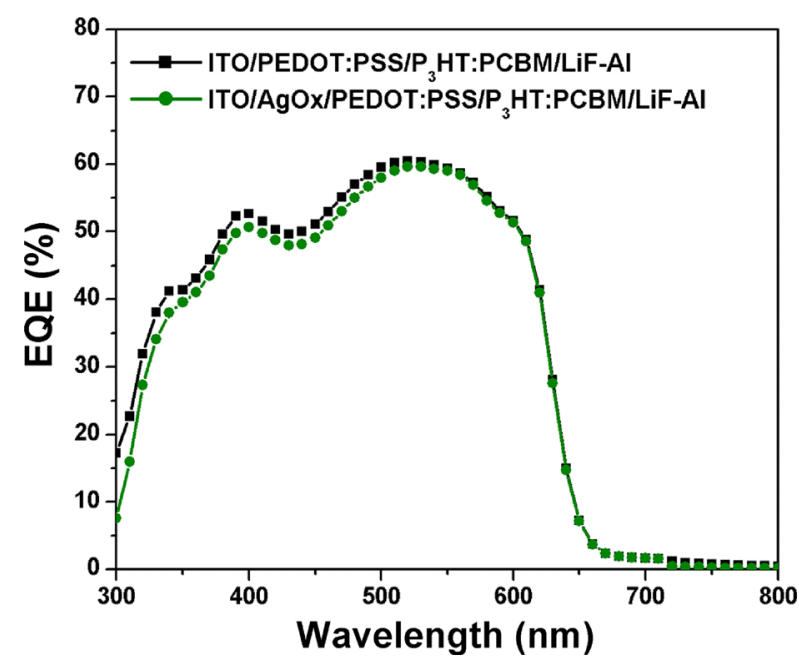

FIG. 7. EQE measurement of the P3HT:PCBM devices using bare ITO and $\mathrm{AgOx} / \mathrm{ITO}$ anodes.
TABLE I. Device parameters of organic solar cells having bare ITO and AgOx modified ITO electrode.

\begin{tabular}{lcccccc}
\hline \hline Anode & $\mathrm{V}_{\mathrm{oc}}(\mathrm{V})$ & $\begin{array}{c}\mathrm{J}_{\mathrm{sc}} \\
\left(\mathrm{mA} / \mathrm{cm}^{2}\right)\end{array}$ & $\mathrm{FF}(\%)$ & $\mathrm{PCE}(\%)$ & $\begin{array}{c}\mathrm{R}_{\mathrm{s}} \\
\left(\Omega \mathrm{cm}^{2}\right)\end{array}$ & $\begin{array}{c}\mathrm{R}_{\mathrm{sh}} \\
\left(\Omega \mathrm{cm}^{2}\right)\end{array}$ \\
\hline ITO & 0.60 & 8.76 & 33 & 1.74 & 28 & 150 \\
AgOx/ITO & 0.58 & 8.64 & 45 & 2.25 & 18 & 587 \\
\hline \hline
\end{tabular}

where $J$ is the current density across the load, $J_{p h}$ is photocurrent, $J_{\mathrm{o}}$ is the saturation current under reverse bias, $R_{S}$ is the series resistance, $R_{s h}$ is the shunt resistance, $n$ is the ideality factor, $\mathrm{q}$ is the electronic charge, $\mathrm{k}_{\mathrm{B}}$ is Boltzmann's constant, and $T$ is the temperature in Kelvin. The source $J_{p h}$ results from the excitation of excess carriers by solar radiation and is proportional to the number of dissociated excitons prior to any recombination. The $R_{s h}$ and $R_{s}$ are important factors in solar cell devices and are used to quantify the quality of the films and their interfaces. In ideal solar cell devices, the series resistance is close to zero while the shunt resistance approaches a high value. The $R_{s h}$ is due to recombination of charge carriers near donor-acceptor interface and at the electrode and is modeled as a leakage current. The charge recombination is a significant parameter and is dependent on ability of the active material to transport separated charge to the electrodes. Series resistance also reflects the ease in which the carrier responds to the electrostatic field (i.e., the mobility) in each specific transport layer and is heavily influenced by the defects and scattering mechanisms. Hence the series resistance depends on the resistivities of the active layer, hole-extraction layer, metal-organic contacts and electrodes. The influence of the interfacial layer on the shunt resistance of the device can be observed in the $J-V$ curves around the $V_{O C}$ and around $J_{S C}$. From the Fig. 6(b), $R_{S}$ and $R_{s h}$ are evaluated as

$$
\begin{aligned}
& R_{S}=\left(\frac{d V}{d J}\right)_{V=V_{O C}}, \\
& R_{S h}=\left(\frac{d V}{d J}\right)_{J=J_{S C}} .
\end{aligned}
$$

The shunt and series resistances values are summarized in Table I for the $\mathrm{AgOx}$ device and the reference device. It is should be noted that the solar cell devices with the $\mathrm{AgOx}$ interfacial layer had a higher $R_{s h}$ value of $586 \Omega \mathrm{cm}^{2}$ when compared to the control device which has a shunt resistance value of $150 \Omega \mathrm{cm}^{2}$. The $R_{s}$ value also decreases in case of solar cell devices with AgOx interfacial layer. This indicates that the $\mathrm{AgOx}$ promotes lower contact resistances of our
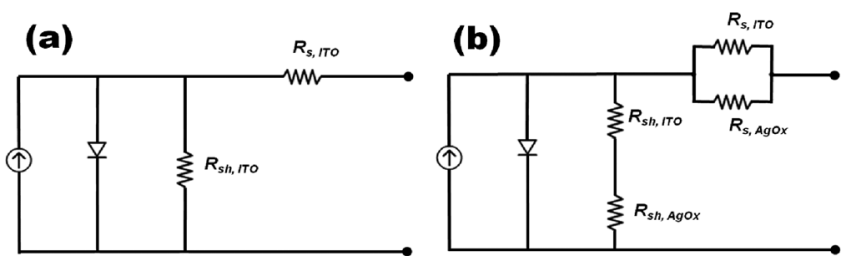

FIG. 8. Equivalent circuit model for solar cells (a) ITO/PEDOT:PSS/ P3HT:PCBM/LiF/Al (b) ITO/AgOx/PEDOT:PSS/P3HT:PCBM/LiF/Al. 
devices by creating an interfacial stepin between PEDOT:PSS and ITO. The lowering of the series resistance has been attributed to the connection of $R_{S, A g O x}$ (series resistance of the device due to addition of AgOx interfacial

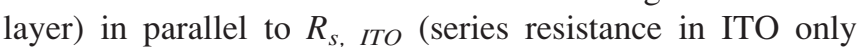
device). Similarly, the increase in shunt resistance has been attributed to the $R_{s h, A g O x}$ in series with $R_{s h, I T O}$, where $R_{s h}$, ${ }_{A g O x}$ and $R_{\text {sh, ITO }}$ are shunt resistances in $\mathrm{AgOx}$ based devices and ITO only devices, respectively.

In a previous investigation by Koide et al., ${ }^{32}$ they compared equivalent circuits for dye-sensitive solar cells to that for the conventional solar cells (see Fig. 8(a)) and included additional capacitive and resistive elements in the total series resistance. After considering that the OSC operates in the DC conditions, they found that the only difference was in the configuration of the series resistance elements. Similarly, our model ignored any capacitive elements and observed a difference in both the series resistance and shunt resistance elements. Future work will focus on optimization of the $\mathrm{AgOx}$ thickness and the implementation of more sophisticated equivalent circuit models that will help to elucidate the effect of new interfacial layers incorporation. These new models will also be used to characterize and optimize the performance of materials selection and device performance.

\section{CONCLUSIONS}

Incorporation of a $\mathrm{AgOx}$ interfacial layer together with PEDOT:PSS effectively extract holes efficiently from the cell by the creation of an interfacial energy step, thus reducing the charge recombination tendency. The devices with the $\mathrm{AgOx}$ interfacial layer demonstrated a $2.25 \%$ increase in their PCE. This increase was a result of the increase of the fill factor from $33 \%$ of the control devices to $45 \%$ in the AgOx modified devices even though they displayed a lower Voc and $J_{S c}$. Comparison of the equivalent circuits for the $\mathrm{AgOx}$ based device and conventional OSC, revealed that the only difference was in the configuration of the resistance elements.

\section{ACKNOWLEDGMENTS}

This research was partially supported by the National Science Foundation (C. Ying, Grant No. DMR-0902277).

${ }^{1}$ C. J. Brabec, N. S. Sariciftci, and J. C. Hummelen, Adv. Funct. Mater. 11, 15-26 (2001).

${ }^{2}$ F. C. Krebs, Sol. Energy Mater. Sol. Cells 93, 394-412 (2009).

${ }^{3}$ H. Y. Chen, J. Hou, S. Zhang, Y. Liang, G. Yang, Y. Yang, L. Yu, Y. Wu, and G. Li, Nat. Photonics 3, 649-653 (2009).
${ }^{4}$ J. Y. Kim, K. Lee, N. E. Coates, D. Moses, T.-Q. Nguyen, M. Dante, and A. J. Heeger, Science 317, 222-225 (2007).

${ }^{5}$ H. Ma, H. L. Yip, F. Huang, and A. K.-Y. Jen, Adv. Funct. Mater. 20, 1371-1388 (2010).

${ }^{6}$ Z. He, C. Zhong, S. Su, M. Xu, H. Wu, and Y. Cao, Nat. Photonics 6, 591-595 (2012).

${ }^{7}$ G. Li, R. Zhu, and Y. Yang, "Polymer solar cells," Nat. Photonics 6, 153-161 (2012).

${ }^{8}$ H. Spanggaard and F. C. Krebs, Sol. Energy Mater. Sol. Cells 83, 125-146 (2004).

${ }^{9}$ S.-I. Na, S.-S. Kim, J. Jo, and D.-Y. Kim, Adv. Mater. 20, 4061-4067 (2008).

${ }^{10}$ Y. J. Cho, J. Y. Lee, B. D. Chin, and S. R. Forrest, Org. Electron. 14, 1081-1085 (2013).

${ }^{11}$ C. J. Brabec, S. E. Shaheen, C. Winder, N. S. Sariciftci, and P. Denk, Appl. Phys. Lett. 80, 1288-1290 (2002).

${ }^{12}$ C. M. Ramsdale, J. A. Barker, A. C. Arias, J. D. MacKenzie, R. H. Friend, and N. C. Greenham, J. Appl. Phys. 92, 4266-4270 (2002).

${ }^{13}$ S. Khodabakhsh, B. M. Sanderson, J. Nelson, and T. S. Jones, Adv. Funct. Mater. 16, 95-100 (2006).

${ }^{14}$ J. S. Kim, J. H. Park, J. H. Lee, J. Jo, D. Y. Kim, and K. Cho, Appl. Phys. Lett. 91, 112111-112113 (2007).

${ }^{15}$ M.-Y. Chang, C.-S. Wu, Y.-F. Chen, B.-Z. Hsieh, W.-Y. Huang, K.-S. Ho, T.-H. Hsieh, and Y.-K. Han, Org. Electron. 9, 1136-1139 (2008).

${ }^{16}$ J. Subbiah, D. Y. Kim, M. Hartel, and F. So, Appl. Phys. Lett. 96, 063303-063305 (2010).

${ }^{17}$ M. T. Dang, L. Hirsch, and G. Wantz, Adv. Mater. 23, 3597-3602 (2011).

${ }^{18}$ Organic Solar Cells: Materials and Device Physics, edited by W. C. H. Choy (Springer, London, 2013), p. 5.

${ }^{19}$ A. C. Arias, M. Granstrom, D. S. Thomas, K. Petritsch, and R. H. Friend, Phys. Rev. B 60, 1854-1860 (1999).

${ }^{20}$ L. S. C. Pingree, B. A. MacLeod, and D. S. Ginger, J. Phys. Chem. C 112, 7922-7927 (2008).

${ }^{21}$ H. Yan, P. Lee, N. R. Armstrong, A. Graham, G. A. Evmenenko, P. Dutta, and T. J. Marks, J. Am. Chem. Soc. 127, 3172-3183 (2005).

${ }^{22}$ M. Jørgensen, K. Norrman, and F. C. Krebs, Sol. Energy Mater. Sol. Cells 92, 686-714 (2008).

${ }^{23}$ E. Voroshazi, B. Verreet, A. Buri, R. Muller, D. Di Nuzzo, and P. Heremans, Org. Electron. 12, 736-744 (2011).

${ }^{24}$ V. Shrotriya, G. Li, C.-W. Chu, and Y. Yang, Appl. Phys. Lett. 88, 073508-073510 (2006).

${ }^{25}$ M. D. Irwin, B. Buchholz, A. W. Hains, R. P. H. Chang, and T. J. Marks, Proc. Natl. Acad. Sci. USA 105, 2783-2787 (2008).

${ }^{26}$ M. Vasilopoulou, A. Soultati, D. G. Georgeiadou, T. Stergiopoulos, L. C. Palilis, S. Kennou, N. A. Stathopoulos, D. Davazoglou, and P. Argitis, J. Mater. Chem. A. 2, 1738-1749 (2014).

${ }^{27}$ W. Wei, X. Mao, L. A. Ortiz, and D. R. Sadoway, J. Mater. Chem. 21, 432-438 (2011).

${ }^{28}$ U. K. Barik, S. Srinivasan, C. L. Nagendra, and A. Subrahmanyam, Thin Solid Films 429, 129-134 (2003).

${ }^{29}$ G. Li, V. Shrotriya, Y. Yao, and Y. Yang, J. Appl. Phys. 98, 043704-043708 (2005)

${ }^{30}$ K.-S. Lee, J.-W. Lim, H.-K. Kim, T. L. Alford, and G. E. Jabbour, Appl. Phys. Lett. 100, 213302-213304 (2005).

${ }^{31}$ V. Shrotriya, J. Ouyang, R. J. Tseng, G. Li, and Y. Yang, Chem. Phys. Lett. 411, 138-143 (2005)

${ }^{32}$ N. Koide, A. Islam, Y. Chiba, and L. Han, J. Photochem. Photobiol. A 182, 296-305 (2006). 